\title{
CAUSAS DA DESNUTRIÇÃO PÓS-GASTRECTOMIA ${ }^{+}$
}

\author{
Sílvia Justina PAPINI-BERTO ${ }^{1}$ e Roberto Carlos BURINI ${ }^{2}$
}

RESUMO - Racional - A retirada total ou parcial do estômago resulta em conseqüências nutricionais, agudas ou crônicas, perfeitamente prognosticáveis, mas nem sempre ponderadas na terapia pós-operatória. Objetivo - Rever as participações mecânicas e químicas do estômago no aproveitamento do nutriente dietético, e as conseqüencias nutricionais da gastrectomia. Resultados - A deficiência energética, com conseqüente perda de peso, acompanha inversamente o volume gástrico remanescente e o tempo pós-operatório; tem a anorexia e diarréia (má absorção) como principais causas, sendo a primeira decorrente de fatores emocionais ou de mediadores químicos de ação hipotalâmica. A diarréia pode ser decorrente da maior motilidade ou do supercrescimento bacteriano intestinais, com o agravante da insuficiência pancreática exócrina e maior esvaziamento da vesícula biliar. A má absorção traz conseqüências não apenas energética-protéica com a perda fecal de gordura e nitrogênio, como também vitamínico-mineral pelo menor aproveitamento da vitamina $D$ e cálcio dietéticos. A anemia verificada no gastrectomizado é conseqüente à diminuição da produção de $\mathrm{HCl}$ (e menor solubilização do ferro) e do fator intrínseco (com menor absorção da vitamina B12). Conclusão - Perda de peso e anemia são os sinais de desnutrição mais comumente observados nestes pacientes, em intensidade e duração variáveis dependentes do tipo de cirurgia e do tempo e tratamento nutricional pós-operatório, sendo recomendável o tratamento dietético supervisionado.

DESCRITORES - Gastrectomia. Desnutrição protéico-energética. Anemia.

\section{INTRODUÇÃO}

A manutenção do bom estado nutricional necessita, obrigatoriamente, da disponibilidade de todos os nutrientes, além de ser necessário que as suas quantidades sejam adequadas às necessidades do corpo naquele momento. Para o organismo receber esses nutrientes é necessário, e igualmente importante, que os alimentos possam ser ingeridos e que a digestão e a absorção se processem normalmente, além de que a incorporação e/ou conversão desses alimentos nos tecidos deve ocorrer harmonicamente. Nesse processo, o tubo digestivo é parte fundamental. A simplificação dos alimentos obedece sucessão de etapas nas quais, cada segmento como, boca, esôfago, estômago, intestino têm, especificamente, sua tarefa funcional ${ }^{(9)}$.
Dos órgãos que compõem o tubo digestivo, o estômago exerce papel de reservatório de alimento. $\mathrm{O}$ alimento sofrerá aí redução de tamanho em partículas menores através da digestão, que é a mistura deles com o suco gástrico. Além disso, o estômago modula a entrada, quantitativa, do quimo no tubo intestinal ${ }^{(6,12,13)}$.

O alimento é processado no estômago mecanicamente por mistura e formação do quimo e, quimicamente, pela secreção de pepsina, ácido clorídrico e do fator intrínseco. Em coordenação com a ação do estômago, o duodeno secreta colecistocinina-pancreozinina (CCK-PZ), mistura o quimo com a bile e as enzimas pancreáticas e absorve alguns minerais. Qualquer alteração das funções do estômago pode levar a danos no processo de digestão, prejudicando no delgado a absorção dos nutrientes ${ }^{(6)}$. Assim, a função digestiva do

Centro de Metabolismo e Nutrição (CeMeNutri) da Faculdade de Medicina da Universidade Estadual Paulista - FM-UNESP, Botucatu, SP.

Nutricionista. Doutora em Ciência dos Alimentos pela Faculdade de Ciências Farmacêuticas da Universidade de São Paulo, São Paulo, SP.

Professor Titular do Departamento de Clínica Médica da FM-UNESP.

Endereço para correspondência: Dr. Roberto Carlos Burini - Centro de Metabolismo e Nutrição - Faculdade de Medicina - UNESP - Caixa Postal 584 - 18618 -970 - Botucatu, SP. 
estômago e duodeno, como todo processo de absorção ficam diminuídas pela gastrectomia ${ }^{(11)}$.

A gastrectomia consiste na retirada de parte ou de todo o estômago, refazendo o trânsito gastrointestinal através de anastomose com o duodeno (Billroth I - BI) ou jejuno (Billroth II - BII). Com a retirada parcial ou total do estômago há remoção de todo antro e conseqüente diminuição na produção de gastrina e redução do estímulo para secreção de pepsina, com prejuízo da digestão de proteínas, principalmente colágeno $^{(6)}$. Ocorre também diminuição da secreção de ácido clorídrico $(\mathrm{HCl})$ e do fator intrínseco.

\section{Conseqüências nutricionais das gastrectomias}

A maioria dos trabalhos que menciona alterações do estado nutricional destes pacientes o faz por meio de observações clínicas, ou referências ao fato feitas pelos próprios gastrectomizados. A grande preocupação destes trabalhos é com a técnica cirúrgica usada $^{(10,21)}$.

Atualmente, observa-se interesse crescente por parte dos pesquisadores em estudar as alterações hormonais no metabolismo energético destes pacientes ${ }^{(1,16,19)}$.

Os sinais e sintomas relacionados ao estado nutricional, mais comumente observados nos pacientes com gastrectomia (Figura 1) são ${ }^{(2,15)}$ :

- anorexia

- diarréia

- síndrome de dumping

- perda de peso

- anemia

- desnutrição protéico-energética

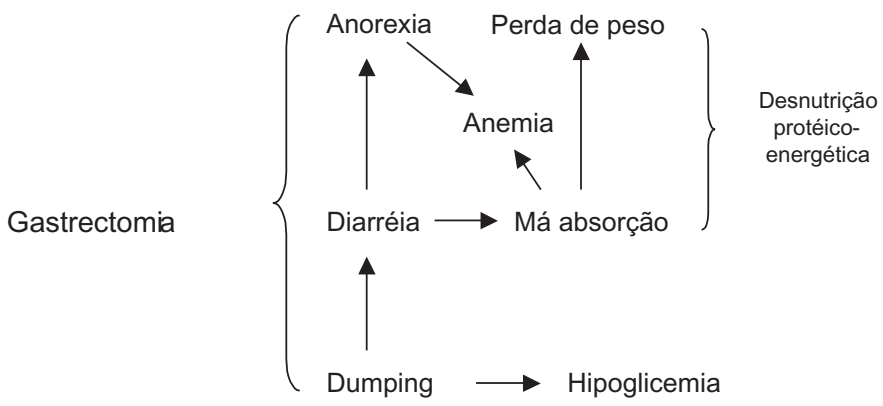

FIGURA 1 - Implicações nutricionais da gastrectomia

\section{Anorexia}

Vários autores demonstram que a diminuição da ingestão alimentar dos pacientes após gastrectomia está relacionada ao temor de comer, como meio de evitar os sintomas pós-prandiais que normalmente apresentam: plenitude e distensão gástrica, diarréia, dor abdominal, sudorese, taquicardia, hipoglicemia ${ }^{(3)}$.

A diminuição da capacidade de armazenamento do estômago causa aparecimento da plenitude gástrica com aumento da distensão abdominal, fator inibidor fisiológico do apetite, contribuindo para diminuição da ingestão alimentar ${ }^{(20,22,24)}$. Além disso, alguns autores ${ }^{(1,}$ 16) verificaram, em pacientes com gastrectomia, aumento na concentração de hormônios e peptídios relacionados com a inibição do apetite. São eles: colecistocinina $(\mathrm{CCK})^{(17,18,20,24)}$ polipeptídio YY (PYY) ${ }^{(17)}$, neurotensina ${ }^{(24)}$.

A CCK é conhecida como hormônio da saciedade por estimular a liberação de calcitonina e oxitocina, também inibidores do apetite, e diminuir o esvaziamento gástrico ${ }^{(17,18,20,24)}$.

MORLEY e MITCHELL ${ }^{(18)}$ verificaram, através de estudos experimentais, que a infusão periférica de PYY aumenta a distensão gastrointestinal, contribuindo para diminuição do apetite.

Outro inibidor fisiológico do apetite é a neurotensina, que age aumentando a atividade simpática ou diminuindo o apetite estimulado pelo jejum, norepinefrina ou dinorfina ${ }^{(24)}$.

\section{Diarréia}

A diarréia constitui problema comum após a cirurgia gástrica. As principais causas estão relacionadas ${ }^{(2,16)}$ :

- ao rápido esvaziamento gástrico, que leva à alteração da função da vesícula biliar com aumento da excreção de sais biliares;

- à má absorção secundária ao supercrescimento bacteriano;

- à insuficiência pancreática exócrina.

WALTHER et al. ${ }^{(23)}$ observaram que a má absorção após a gastrectomia, atinge $80 \%$ dos pacientes no pós-operatório imediato, sendo transitória, regredindo 1 a 6 meses após a cirurgia, podendo ser protéica ou de gordura.

A diminuição da acidez gástrica contribui para o aumento das bactérias intestinais, provocando diarréia, podendo resultar em má absorção. Assim, a má absorção protéica pode ser conseqüência também, do crescimento bacteriano anaeróbico que promove desaminação e produção de uréia a partir da proteína dietética ${ }^{(2)}$.

A menor secreção gástrica, diminuição de $\mathrm{HCl}$ e de gastrina levam à redução da secreção de pepsina, enzima iniciadora da digestão protéica, e o aumento do trânsito intestinal leva à má absorção de proteínas com aumento da perda fecal de nitrogênio. Por outro lado, também o prejuízo da função pancreática pode contribuir para má absorção de nitrogênio ${ }^{(7)}$.

Outras causas de diarréia após a gastrectomia estão relacionadas às alterações estruturais da mucosa intestinal e à produção deficiente de lactase pelo intestino ${ }^{(3,11)}$. 


\section{Síndrome de dumping}

O conjunto de sinais e sintomas que surgem logo após as refeições, caracterizado pela sensação de desconforto abdominal, fraqueza e tremores, sudoreses, taquicardia, palidez e vertigem, que melhoram com o decúbito, é conhecida como síndrome de dumping ${ }^{(2,16)}$.

A alteração no esvaziamento gástrico após a cirurgia constitui causa central dos sintomas apresentados. A incidência e gravidade dos sintomas parece ser proporcional à velocidade do esvaziamento gástrico. Em indivíduos normais, o esvaziamento gástrico é regulado pelo tônus fúndico, mecanismo antropilórico de "feedback" duodenal. No paciente com gastrectomia esses mecanismos estão totalmente $\operatorname{alterados}^{(2,14)}$.

$\mathrm{O}$ rápido esvaziamento gástrico pode refletir em liberação inapropriada dos hormônios intestinais, que propiciam os sintomas gastrointestinais ou vasomotores (plenitude e distensão gástrica, dor abdominal, diarréia, sudorese, taquicardia, etc). Esses sintomas podem aparecer logo após a refeição (precoce) ou algumas horas após (tardio). Os precoces ocorrem cerca de 10 a 30 minutos após a ingestão da refeição, sendo resultado da passagem rápida do quimo hiperosmolar para o intestino delgado, promovendo seqüestro do fluído intraluminal. Estas alterações diminuem o volume plasmático, levando à hipotensão e taquicardia, e também à distensão abdominal com conseqüente dor e diarréia ${ }^{(2)}$.

Sabe-se que os hormônios intestinais estão aumentados por mecanismos ainda não bem conhecidos ${ }^{(2)} \mathrm{e}$, também que a liberação pós-prandial de enteroglucagon, peptídio insulinotrópico glicosedependente, polipeptídio pancreático, polipeptídio intestinal vasoativo, peptídio liberador de gastrina, serotonina, bradicina, e motilina estão aumentados nos pacientes com gastrectomia. Todos eles contribuem para o aumento da motilidade intestinal ${ }^{(1,19)}$

Os sintomas de dumping tardio ocorrem de 2 a 3 horas após a refeição e o mecanismo de ação proposto é que o rápido esvaziamento gástrico leva a maior oferta de carboidratos ao intestino delgado proximal. A glicose, rapidamente absorvida, resulta em hiperglicemia com conseqüente liberação excessiva de insulina, provocando, como "rebote"(em 2 a 3 horas), a hipoglicemia. Os peptídios que mediam esses efeitos incluem colecistocinina, enteroglucagon, peptídio insulinotrópico glicose-dependente e "glucagon-like peptide" $(\mathrm{GLP})^{(2,16)}$.

O sintomas da síndrome de dumping, principalmente o desconforto abdominal, podem resultar em redução alimentar e agravar o estado nutricional do paciente ${ }^{(3,19)}$.

\section{Perda de peso}

A perda de peso é a expressão direta do déficit energético, podendo se estabilizar alguns meses depois da cirurgia e ficar, muitas vezes, situado abaixo do peso pré-operatório ${ }^{(14,15)}$. É descrito que cerca de $35 \%$ dos pacientes perdem peso após gastrectomia, não o recuperando totalmente, o que pode estar relacionado diretamente à redução da ingestão alimentar e à má absorção de nutrientes, além de ser conseqüência da doença de base ${ }^{(3)}$.

Quando a gastrectomia é realizada apenas para tratamento de úlcera péptica, sem qualquer outra condição mórbida associada, a perda de peso não aparece ser acompanhada de alterações na bioquímica do sangue, em especial nas taxas de proteínas plasmáticas.

\section{Anemia}

Os pacientes com gastrectomia podem desenvolver, ao longo do tempo, anemia decorrente da ressecção gástrica. Esta pode ser ferropriva ou megaloblástica ${ }^{(10,15)}$. A anemia ferropriva é conseqüente à diminuição da produção de $\mathrm{HCl}$, responsável por favorecer a absorção de ferro, mantendo-o na forma ferrosa, que é melhor absorvido ${ }^{(4,5)}$. A absorção pode também ser prejudicada na gastrectomia Billroth II, visto que o ferro é absorvido no duodeno(15) . A diminuição da ingestão alimentar, com conseqüente diminuição da ingestão de ferro, também contribui para o desenvolvimento da anemia ferropriva ${ }^{(10,15)}$

A anemia megaloblástica pode ser conseqüente à retirada da mucosa gástrica responsável pela produção do fator intrínseco, fundamental à absorção de vitamina B12 no íleo terminal ${ }^{(2,4,8)}$. Quando da reconstrução do trânsito, através de anastomose com o jejuno, também a alça cega, formada pelo duodeno, pode favorecer a síndrome de proliferação bacteriana, contribuindo desta forma, para a diminuição de absorção de vitamina $\mathrm{B} 12^{(2,8,15)}$.

\section{CONSIDERAÇÕES FINAIS}

Pela importância das funções mecânica e química do estômago no trato digestório, são esperadas conseqüências nutricionais, face aos mecanismos aqui levantados. Como essas conseqüências são previsíveis e em intensidades dependentes do tempo pós-operatório e do volume gástrico remanescente, o tratamento nutricional torna-se viável e, portanto, mandatório, o que no entanto, nem sempre é lembrado, prescrito, ou cumprido integralmente, permitindo a instalação ou agravamento da desnutrição iatrogênica desses pacientes. 
Papini-Berto SJ, Burini RC. Causes of malnourishment in post-gastrectomyzed patients. Arq Gastroenterol 2001;38(4):272-275.

ABSTRACT - Background - The stomach through its mechanical and chemical processes has an unique role in the food processing and bioavailability. Hence gastrectomy has predictable and modifiable nutritional consequences depending upon its knowledge and the postsurgery therapies. Objective - To point out the impact of gastrectomy on the nutritional status focusing on both mechanical and chemical actions of stomach on intaked foods. Results - The protein-energy malnutrition and consequent body-weight loss follow reversely the remainer gastric volume and post-operatory length and have anorexy and intestinal malabsorption as their main causes. Lower food intake is probably due to either emotional factors or chemical mediators acting centrally on hypothalamus. The diarrhea may be due to either increased peristalsis or bacterial overgrowth both aggravated by exocrine-pancreas deficiency and gallbladder overflow. The intestinal malabsorption leading to fecal losses of fat and/or nitrogen as well as lower utilization of dietary calcium and liposoluble vitamins. The gastrectomy-related anemia is consequent to lower secretion of both $\mathrm{HCl}$ and intrinsic factor leading to a decreased solubilization of iron and lower absorption of vitamin B12, respectively. Conclusion-Body-weight loss and anemia are the protein-energy malnutrition findings often found in these patients whose severity and lasting depend upon the type of surgery, post-surgery length and received nutritional care, being strongly recommended a supervisioned dietary care.

HEADINGS - Postgastrectomy syndromes. Protein-energy malnutrition. Anemia. Nutrition disorders.

\section{REFERÊNCIAS BIBLIOGRÁFICAS}

1. Andreasen JJ, Orskov C, Holst JJ. Secretion of glucagon-like peptide - 1 and reactive hypoglycemia after partial gastrectomy. Digestion 1994;55:221-8.

2. Carvajal SH, Mulvihill SJ. Postgastrectomy syndromes: dumping and diarrhea. Gastroenterol Clin North Am 1994;23:261-79.

3. Cristallo M, Braga M, Agape D. Nutrition status, function of the small intestine and jejunal morphology after total gastrectomy for cancinoma of the stomach. Surg Gynecol Obstet 1986;163:225-30.

4. Desai MB, Jeejeebhoy KN. Peptic ulcer. In: Shils ME, Olson JA, Shike M, editors Modern nutrition in health and disease. 8. ed. Philadelphia: Waverly; 1994. v.1, p.237-41.

5. Fairbanks VF. Iron in medicinec and nutrition. In: Shils ME, Olson JA, Shike M, editors. Modern nutrition in health and disease. 8. ed. Philadelphia: Waverly; 1994. v.1, p.185-211.

6. Feldman M. Gastric secretion in health and disease. In: Sleisenger MH, Fordtran JS, editors. Gastrointestinal disease, pathophysiology, diagnosis, management. 4. ed. Philadelphia: WB Saunders; 1989. p.713-29.

7. Friess H, Bühm J, Müller MW, Glasbrenner B, Riepl RL, Malfertheiner P, Büchler MW. Maldigestion after total gastrectomy is associated with pancreatic insufficiency. Am J Gastroenterol 1996;91:341-7.

8. Green R. Screening for vitamin B12 deficiency: caveat emptor. Ann Intern Med 1996;124:509-11.

9. Guyton AC. Gastrointestinal physiology. In: Guyton A. Textbook of medical physiology. Philadelphia: WB Saunders; 1991. p.687-742.

10. Holstein CS, Von Walther B, Ibrahimbegovic E, Akesson B. Nutrition status after total and partial gastrectomy with Roux-in-Y reconstruction. Br J Surg 1991;78:1084-7.

11. Leth R, Abrahansson H, Kilander A, Lundele L. Malabsorption of fat after partial gastric resection. Eur J Surg 1991;157:205-8.

12. Mc Callum RW. Motor function of the stomach in health and disease. In: Sleisenger MH, Fordtran JS, editors. Gastrointestinal disease patophy- siopatology, diagnosis, management. 4. ed. Philadelphia: WB Saunders; 1989. p.675-713.

13. Mc Guigan JE, Ament ME. Anatomy, embryology, and developmental anomalies. In: Sleisenger MH, Fordtran JS, editors. Gastrointestinal disease patophysiopatology, diagnosis, management. 4. ed. Philadelphia: WB Saunders; 1989. p.659-75.

14. Meyer JH. Chronic morbidity after ulcer surgery. In: Sleisenger MH, Fordtran JS, editors. Gastrointestinal disease patophysiopatology, diagnosis, management. 4. ed. Philadelphia: WB Saunders; 1989. p.962-83.

15. Meyer JH. Nutrition outcomes of gastric operations. Gastroenterol Clin North Am 1994;23:227-60

16. Miholic J, Orskov C, Holst JJ, Kotzerke J, Meyer JH. Emptying of the gastric substitute, glucagon-like peptide - 1 (GLP-1), and reactive hypoglycemia after total gastrectomy. Dig Dis Sci 1991;36:1361-70.

17. Morley JE. Appetite regulation by gut peptides. Annu Rev Nutr 1990;10:385-95.

18. Morley JE, Mitchell JE. Neurotransmitter/neuromodulator influence on eating. Adv Biosci 1985;60:11-9.

19. Nordback I, Harju E. Immediate effect of vagotomy on pancreatic insulin secretion. Gut 1991;32:303-5.

20. Stricker EM, Verbalis JG. Control of appetite and satiety: insights from biologic and behavioral studies. Nutr Rev 1990;48:49-55.

21. Tanaka T, Fujiwara Y, Nakagawa K, Kusunoki M, Utunomiya J. Reflux esophagitis after total gastrectomy with jejunal pouch reconstruction: comparision of long and short pouches. Am Gastroenterol 1997;92:821-4.

22. York DA. Metabolic regulation of food intake. Nutr Rev 1991;48:64-70.

23. Walther B, Clementsson C, Vallgren S, Ihse I, Akesson B. Fat malabsortion in patients before and after total gastrectomy studied by the triolein breath test. Scand J Gastroenterol 1989;24:309-14.

24. Wilber JF. Neuropeptides, appetite regulation and human obesity. JAMA 1991;266:257-9.

Recebido em 14/5/2001 Aprovado em 30/7/2001. 